\title{
Significance of intermediate forms in phyletic reconstruction of ammonites: Early Jurassic Phricodoceras case study
}

\author{
Jean-Louis Dommergues and Christian Meister \\ Acta Palaeontologica Polonica 58 (4), 2013: 837-854 doi: http://dx.doi.org/10.4202/app.2011.0148
}

This paper discusses the phyletic interpretation of the genus Phricodoceras and its taxonomic classification at the subfamily, family, and superfamily levels from an historical and critical perspective. First a review of the latest findings on this taxon is presented and the grounds for the attribution of Phricodoceras to the Schlotheimiidae (Psiloceratoidea) are summarized and illustrated. This review is a synthesis grounded on evolutionary (e.g., heterochronies, innovations), eco-ethological (e.g., assumed shell hydrodynamic capacities) and spatio-temporal patterns (e.g., bio-chronostratigraphy, palaeobiogeography). Then, the main stages of understanding the taxonomy of Phricodoceras since the early nineteenth century are reviewed. Two main taxonomic concepts alternate over time. The first is based on the "overall resemblance" of Phricodoceras to some coeval Eoderoceratoidea leading to the genus being included in its own family or subfamily (e.g., Phricodoceratinae) among the Eoderoceratoidea. The second hypothesis, recently confirmed by the discovery of an intermediate form (i.e., Angulaticeras spinosus ), clearly includes Phricodoceras within the Schlotheimiidae (Psiloceratoidea). Comparison of these two very different conceptions reveals how "overall resemblance" can be misleading and shows that the discovery of intermediate forms is often the key to phyletic reconstructions in ammonites.

Key words: Cephalopoda, Ammonoidea, stratigraphy, paleobiogeography, taxonomy, character, homology, ontogeny, adaptation, Jurassic.

Jean-Louis Dommergues [Jean-Louis.Dommergues@u-bourgogne.fr], UFR Sciences Vie, Terre et Environnement, Université de Bourgogne, CNRS/uB, UMR 5561, Biogéosciences Dijon, 6 Boulevard Gabriel, F-21000 Dijon, France; Christian Meister [christian.meister@ ville-ge.ch], Muséum d'Histoire Naturelle de Genève, Département de Géologie et de Paléontologie, 1 Rte de Malagnou, cp 6434, CH-1211 Geneva, Switzerland. 
This is an open-access article distributed under the terms of the Creative Commons

Attribution License (for details please see creativecommons.org), which permits unrestricted use, distribution, and reproduction in any medium, provided the original author and source are credited.

Forif Full text $(1,504.0 \mathrm{kB})$ 